\section{Bladder stone: still a rare cause of obstructed labour}

\author{
Sonika Mann, ${ }^{1}$ Amit Mann, ${ }^{2}$ \\ Pushpa Dahiya, ${ }^{1}$ Krishna Dahiya ${ }^{1}$ \\ ${ }^{1}$ Department of Obstetrics and \\ Gynaecology; ${ }^{2}$ Department \\ of Nephrology, Post Graduate Institute \\ of Medical Sciences (PGIMS), Rohtak, \\ Haryana, India
}

\begin{abstract}
Bladder stone is still a rare cause of obstetrical dystocia. We report a rare case of obstructed labour due to a huge bladder stone. Diagnosis was confirmed only at the time of cesarean section because of the unusual posterolateral location of the stone, which was impacted below the fetal head thus obstructing labour. A bladder stone weighing $140 \mathrm{~g}$ and measuring $9 \times 6 \times 5 \mathrm{~cm}^{3}$ was removed by cystolithotomy at the time of cesarean section. The postoperative period was uneventful.
\end{abstract}

\section{Introduction}

Obstructed labour due to mechanical dystocia is a very common entity. Bladder stone as a cause of obstructed labor is very rare $^{1}$ and very few cases have been reported in literature. In neglected cases, serious injury has occurred, even causing vesicovaginal fistula., ${ }^{2,3}$ Timely diagnosis and early cesarean section to prevent bladder injury is important.

\section{Case Report}

A 28-year-old second gravida unbooked patient was referred for obstructed labour from a primary health center. She had had a normal vaginal delivery at home in her first pregnancy. In her second pregnancy, apart from a few episodes of hematuria in the last two months, her antenatal period was uneventful. On presentation she had been in labour for $12 \mathrm{~h}$ and there had been a premature rupture of fetal membranes $2 \mathrm{~h}$ earlier. On admission the patient was dehydrated, her pulse rate was 110 per min and blood pressure was 100/70 $\mathrm{mm} \mathrm{Hg}$. The uterus was term size and she was having 3 good intensity uterine contractions every 10 min each lasting for 40-45 sec. A bandls ring was observed reaching up to the umbilicus. A single fetus was in cephalic presentation and fetal heart rate was heard at 146 beats per min regular. Vaginal examination revealed a fully dilated cervix, the fetal head was at level 0 and a bulge was felt in the right ishchiorectal fossa. A hard bony fixed mass could be felt on the posterolateral vaginal wall impacted below the fetal head. The origin of the mass was thought to be probably from pelvic bone. The bladder was catheterized with a Foley's catheter and hematuria was observed. The head could not be pushed below the immobile mass and it was decided to perform an emergency cesarean section. A male neonate was delivered weighing $2.9 \mathrm{~kg}$ with APGAR score of 4 and 8 at one and five minutes. Efforts were made to locate the mass. It was fully mobile within the pelvic cavity and was found lying in the bladder (Figure 1). A final diagnosis of bladder stone as cause of obstructed labour was made. Cystolithotomy was performed and a stone measuring $9 \times 6 \times 5 \mathrm{~cm}$ and weighing $320 \mathrm{~g}$ was removed (Figure 2). The bladder was repaired in two layers with vicryl 3-0. The bladder was drained by both suprapubic and a Foley's catheter. The suprapubic catheter was removed on Day 10 and the Foley's catheter was maintained for over 21 days. The patient was given $3^{\text {rd }}$ generation cephalosporins for seven days in the post-operative period and diclofenac suppository was given for pain relief. Patient recovery was uneventful.

\section{Discussion}

A huge bladder stone presenting during obstructed labour without any prior symptoms

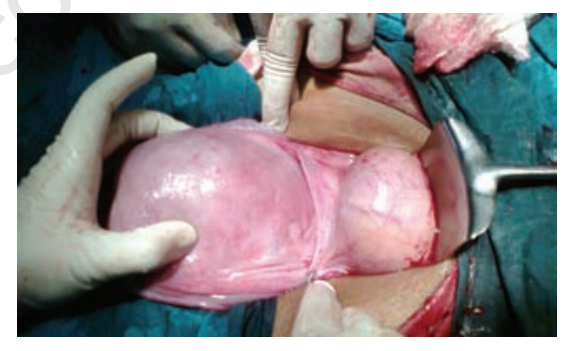

Figure 1. Bladder stone after cesarean section.

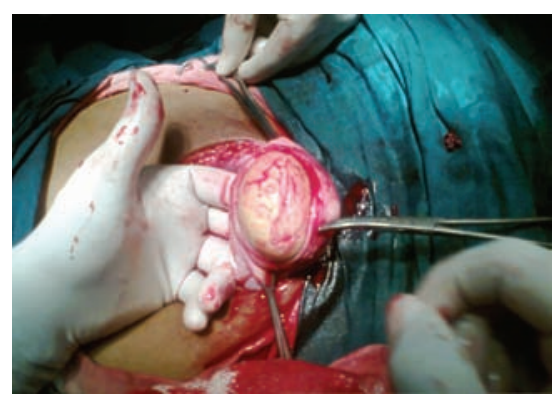

Figure 2. Cystolithotomy.
Correspondence: Sonika Mann, Department of Obstetrics and Gynaecology, Post Graduate Institute of Medical Sciences (PGIMS), no 138/22 vikas nagar Rohtak, Haryana, India.

Tel: 91.9896004974.

E-mail: drsonikamann@gmail.com

Key words: bladder stone, obstetrical dystoci, obstructed labour.

Received for publication: 27 June 2011.

Revision received: 14 December 2011.

Accepted for publication: 16 December 2011.

This work is licensed under a Creative Commons Attribution NonCommercial 3.0 License (CC BYNC 3.0).

(C) Copyright S. Mann et al., 2012

Licensee PAGEPress, Italy

Urogynaecologia 2012; 26:e1

doi:10.4081/uij.2012.e1

of urinary tract infection is very unusual. ${ }^{4} \mathrm{~A}$ combination of urinary symptoms and location of tumor of a hard bony consistency points to vesical calculus. This may sometimes become deeply impacted between the fetal head and the pubic bone simulating a bone tumor and confusing the diagnosis. ${ }^{5}$ As in our case, the tumor was deeply impacted and pushed in the posterolateral vaginal wall. This led us to hypothesize a bone origin of the tumor. Ultrasound investigation may help to establish a pre-operative diagnosis in these cases.

\section{Conclusions}

Timely intervention in this patient prevented maternal morbidity as spontaneous rupture of the bladder to expel the stone can occur and a vesicovaginal fistula can also be formed.

\section{References}

1. Yassir AB, Abderrahim A, Hassan A. Bladder stone: uncommon cause of mechanical dystocia. Arch Gynecol Obstet 2006;274:323-4.

2. Seth $\mathrm{S}$, Malik $\mathrm{S}$, Salhan $\mathrm{S}$. Vesical calculus causing dystocia. Eur J Obstet Gynecol Reprod Biol 2002;101:199-200.

3. Penning SR, Cohen B, Tewari D, et al. Pregnancy complicated by vesical calculus and vesicocutaneous fistula. Am J Obstet Gynecol 1997;176:728-9.

4. Serinelli A. Dystocia due to a large calculus of the bladder. Minerva Ginecol 1968;20:37-40.

5. Sarma V, Chir B. Vesical calculus as a cause of labour dystocia. Postgrad Med J 1960;626-8. 